\title{
More Science, Less Exegesis, Please: A Rejoinder*
}

\author{
Tak Wing Chan \\ Department of Social Science \\ UCL Institute of Education
}

May 7, 2019

I thank Professors Shyon Baumann, Magne Flemmen, Laurie Hanquinet, Vegard Jarness, Irmak Karademir-Hazir, Paul Lambert, Omar Lizardo, and Lennart Rosenlund for their comments on my paper 'Understanding Cultural Omnivores: Social and Political Attitudes' (Chan, 2019a). I will start with a brief recap of what I set out to do in that paper and my main findings.

My goal is to adjudicate between two competing interpretations of cultural omnivorousness. Is it a novel way to draw social boundaries; a new expression of social superiority? Or perhaps omnivorousness has very little to do with distinction. In which case, omnivores are simply more open and tolerant people who want to try out different cultural styles.

There is no survey evidence that would directly reveal what omnivorousness means. So my strategy is to explore the views of omnivores across a range of related issues. To borrow an expression of DiMaggio (1996, p. 161), I want to understand how omnivorousness is 'embedded in larger systems of meaning'. To this end, I report the following findings. Compared to paucivores and, especially, univores, omnivores hold more favourable views about the European Union, and they tend to eschew national identities. Omnivores are also more trusting and risk-taking. In terms of the Big Five personality traits, they are more extravert, more open to new experiences, and less conscientious. These findings suggest that omnivores are more open and cosmopolitan than others in their general outlook.

Omnivores are politically engaged. But they are not especially class conscious. Their views on income distribution are not particularly left-wing or right-wing. Compared to univores or paucivores, omnivores are not more

*I thank John Goldthorpe for helpful suggestions. 
status-conscious, in the sense that the two most important status-conferring attributes, i.e. profession and education, are not especially salient to them. What exercise omnivores are postmaterialist issues, such as environment and climate change, gay rights, and gender equality. On the basis of these results, I argue that cultural omnivorousness is better seen as an expression of cosmopolitan postmaterialism rather than a new form of distinction in the Bourdieusian sense.

My colleagues in this special section take issues with me on many fronts. Given the space constraint, I can only respond to some of their more pertinent points.

\section{Research question}

Karademir-Hazir argues that the key question is not so much the meaning of cultural omnivorousness as the role of culture in the reproduction of inequality: "what matters is whether or not the embodiment of a certain cultural disposition grants advantages in other social fields' (p. XXX). How much cultural consumption pays is indeed an interesting question. But, alas, that is not the research question that I choose to address in my paper.

I note that Reeves and de Vries (2019) have recently provided some answers to Karademir-Hazir's question. Using Understanding Society data, they show that, net of socio-demographic background, education, social class, etc, taking part in one more type of cultural activity is associated with an earnings increase of $£ 18$ to $£ 25$ per month (Reeves and de Vries, 2019, p. 228, Table II). This return to cultural consumption seems pretty modest to me. Moreover, it is probably an over-estimate as Reeves and de Vries' model is vulnerable to omitted variable bias.

\section{Latent class analysis}

A second set of criticisms concerns my latent class analysis (LCA). In response to my observation that 'a majority ... of individuals in advantaged positions do not consume highbrow culture at all', Karademir-Hazir suggests "link[ing] legitimacy to the tastes of the highly educated and defin[ing] what should be considered as "highbrow" in that particular sample' (p. XXX). Similarly, Hanquinet suggests that video games, rap and rock, street art, etc are emerging forms of highbrow culture.

Karademir-Hazir and Hanquinet are certainly right that the definition of highbrow (or middlebrow or popular) culture is not frozen in time. But these 
cultural categories do not change all that quickly or haphazardly either. I accept that some indicators of my LCA are not ideal. For example, 'rock, pop, and jazz' is a very broad and heterogeneous indicator. I would love to have more fine-grained measures, e.g. separate indicators for 'jazz' and for 'rock and pop'. But, imperfect as this indicator is, I would maintain that most people do not see 'rock, pop, and jazz' as being on a par with classical music or opera. And I would be very surprised if video games, rap music, and street art are widely regarded as forms of highbrow culture.

More importantly, if we were to follow Karademir-Hazir's suggestion and treat whatever the highly educated consume as highbrow, then of course the highly educated consume nothing but highbrow culture. In which case, Bourdieu's class-culture homology argument would always be true, but at the cost of being turned into a tautology.

Lambert also questions my LCA. Because he sees omnivorousness as 'more naturally a continuous dimension' ( $\mathrm{p}$. XXX), he argues that my tripartite division of the respondents into omnivores, paucivores, and univores 'might diminish the accuracy of the relevant estimated associations' (p. XXX).

There are indeed different ways to think about and measure omnivorousness. I use LCA for two reasons. First, scholars in the field often refer to distinct types of cultural consumers. Secondly, the conditional probabilities of the LCA solution allow you to check, quite directly, whether there are people who are likely to consume both highbrow and popular culture. This speaks to a key insight of Peterson, namely the boundary-crossing nature of omnivores' cultural consumption. Having said that, it is possible to think of everyone as being a little more or less omnivorous, rather than of one type or another. One way to capture this idea is to count just how many types of cultural consumption people do. Let's call this the volume measure of omnivorousness. Whether the two measures (i.e. latent class and volume) make any difference to the results is an empirical matter.

Figure 1 shows how the two measures map onto each other. As might be expected, omnivores generally score higher on the volume measure than do paucivores who, in turn, score higher than univores. But it is also clear that the three latent classes are very well separated according to the volume measure. There is, for example, no overlap at all in their interquartile range. Given this, I would argue that thinking in terms of three discrete latent classes is not unreasonable. I have re-run some (but not all) regressions reported in the paper using the volume measure of omnivorousness, and have obtained very similar results. I strongly suspect that using the volume measure that is favoured by Lambert will not change the overall conclusion of my paper. (Perhaps this could be a dissertation project for an undergraduate or a MSc student with some basic quantitative skills. Any taker?) 


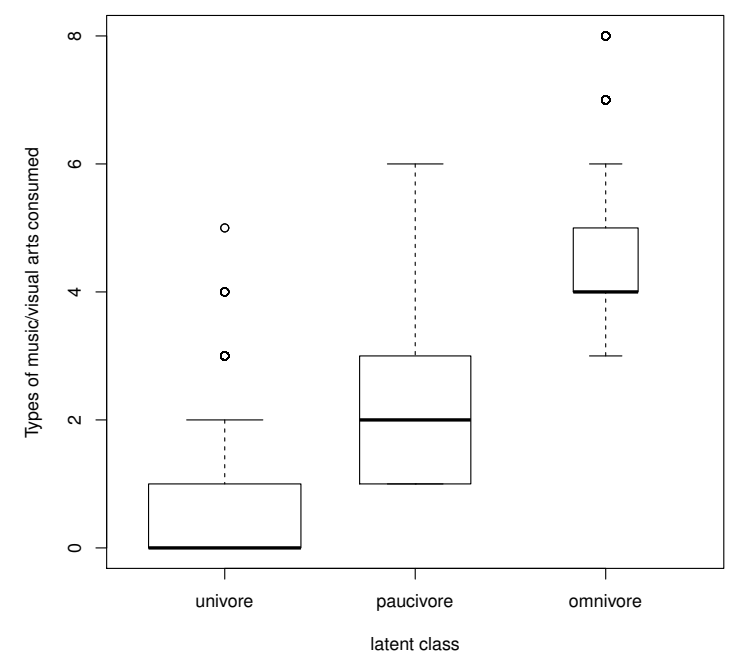

Figure 1: Boxplot showing the distribution of the volume of cultural consumption by latent class

Let me quickly deal with some other points raised by Lambert. All regression models reported in the paper take age into account. So the confounding between age and education is not as problematic as he suggests. I have explored the implications of intergenerational educational mobility for cultural omnivorousness elsewhere (Chan and Turner, 2017). As regards whether class and status are analytically and empirically separable, please see my reply to Flemmen, Jarness, and Rosenlund (FJR) in this issue (Chan, 2019b).

\section{Distinction, 'poor door', and evidence}

Baumann is very complimentary of both my paper and FJR's: 'tremendous data sets', 'careful, highly expert approach to data analysis', 'significant advances in our understanding', and so on (p. XXX). But he flatly rejects the conclusion that I draw: "it is not clear that we can draw the conclusion that if omnivorousness is about cosmopolitanism and openness, it is therefore not about status distinction ... omnivorous cultural consumption simultaneously expresses egalitarian and democratic impulses and status distinction' (p. XXX).

Baumann is, of course, free to define distinction however he wants. It is hard for me to imagine a form of distinction that draws symbolic boundaries on the one hand and 'expresses egalitarian and democratic impulses' on the 
other. But perhaps that just reflects a lack of imagination on my part. That said, if distinction of this 'egalitarian and democratic' type exists, it would be quite different from how Bourdieu sees it. A fair reading of the following passages would suggest that distinction, as articulated by Bourdieu, involves a good deal of condescending attitudes.

The denial of lower, coarse, vulgar, venal, servile - in a word, natural - enjoyment, which constitutes the sacred sphere of culture, implies an affirmation of the superiority of those who can be satisfied with the sublimated, refined, disinterested, gratuitous, distinguished pleasures forever closed to the profane. That is why art and cultural consumption are predisposed, consciously and deliberately or not, to fulfil a social function of legitimating social differences (Bourdieu, 1984, p. 7).

' $[\mathrm{T}]$ he higher the level of education, the greater is the proportion of respondents who, when asked whether a series of objects would make beautiful photographs, refuse the ordinary objects of popular admiration - a first communion, a sunset or a landscape - as "vulgar" or "ugly", or reject them as "trivial", silly, a bit "wet" ...' (Bourdieu, 1984, p. 35).

Along a similar line as Baumann, FJR argue that 'cultural distinction does not presuppose overt displays of feelings of superiority or anything similar ... snobbery is strained and explicit, whereas true distinction is characterized by a more implicit, subtle "ease" and "naturalness"' (p. XXX). I am not sure what FJR have in mind. But consider this: Asquith, Prime Minister of the UK between 1908 and 1916, famously describes the men of his alma mater, Balliol College, Oxford, as possessing 'a tranquil consciousness of effortless superiority.' Is that strained snobbery or a condescension that is natural and at ease with itself? It seems pointless to ponder this question for more than a second.

In any case, let us not forget that social status can be very much in-yourface too. Take the example of 'poor door' in cities like London or New York. The planning authorities of these cities often require luxury flats developers to include a number of affordable units on the same site. In some of these mixed developments, residents of the luxury flats use the swanky entrance with concierge. Residents of the affordable flats, however, are banished to the side-entrance (hence the 'poor door'); and they do not have access to many on-site facilities, such as car park, gym, pool, or even lifts (Osborne, 2014; Schwartz, 2016; Booth and Mohdin, 2019). Clearly, people who pay 
millions for a flat do not want to be seen mixing with hoi polloi. There are even reports of communal playground being divided by hedges, so that the children of private home owners do not mix with the children of social housing tenants (Grant, 2019). ${ }^{1}$

Thus, social status is very much alive and well. The question is whether cultural omnivores are more likely than univores or paucivores to approve of, and take part in, such not-so-subtle status display. As mentioned already, there is no survey data that would directly answer that question. But what about the larger-systems-of-meaning evidence that I offer? FJR are very sceptical about them, because 'attitudes to politics and morals do not directly reflect attitudes to the cultural-aesthetical domain' (p. XXX).

Fair enough. I believe those findings are relevant. FJR do not. Social science being what it is, different interpretations and judgements are sometimes unavoidable. Reasonable people could disagree on such matters. But what sorts of evidence would FJR accept as being adequate to the task? They suggest that '[a] promising path to this end may be to frame questions of distinction and openness in terms of what Lamont ... has called symbolic boundary work ... the Lamontian approach involves generating qualitative interview data that allow for valid assessments of research questions of the type raised by Chan' (p. XXX).

Qualitative interviews are indeed useful. I have quoted in my paper some prominent Bourdieusian scholars who draw on qualitative interview data and come to a conclusion that is similar to mine. It is worth quoting them again.

' $[\mathrm{O}]$ mnivorousness accompanies tolerance; there was no evidence of the drawing of cultural boundaries to exclude other social groups, and few indications of snobbishness when expressing personal cultural tastes' (Warde et al., 2007, p. 158)

'[T] hose who were culturally engaged did not articulate a clear sense of cultural superiority ... [W]e find no one remotely corresponding to the figure of the snob ... These observations imply dynamics [that are] different from those described by Bourdieu' (Bennett et al., 2009, pp. 66, 70-71).

It is not clear whether FJR are persuaded by Warde et al. (2007) or Bennett et al. (2009), as they are not mentioned at all. Does this not suggest

\footnotetext{
${ }^{1}$ These recent news stories about 'poor doors' are reminiscent of the infamous Cutteslowe Walls in Oxford (Plowman et al., 1962; Collison, 1963). Those walls, over two metres tall and with spikes on top, were built in 1934 by a private developer in order to block off the council tenants of the nearby Cutteslowe estate. The walls were bitterly resented and fought over until their demolition in 1959, see www.bbc.co.uk/oxford/content/articles/2009/03/26/cutteslowe_feature.shtml
} 
that FJR are determined to discount any evidence, quantitative or qualitative, that challenges their views?

FJR also say that I misrepresent my own findings. Here is the charge.

'Chan also claims misleadingly that omnivores do not attach any great significance to these sources of identity: however, Figure 4 reveals that on all levels of education, and in all three consumption groups, a very large majority considers their profession important to their identity. It is correct that omnivores do not report this more often than others but they still have a predicted probability of about 0.8 to say that it is of importance. Accordingly, it would be more correct to say that if identifying with one's profession makes one status conscious, then omnivores are highly status conscious - and so is everyone else' (p. XXX).

And this is what I wrote. 'When asked what is important to the sense of who they are, the two most important status-conferring attributes, i.e. profession and education, are not more salient to omnivores than to others' (p. XXX); 'compared to univores, omnivores and paucivores are not especially status-conscious individuals' (p. XXX); 'omnivores are not more status-conscious than univores' ( $\mathrm{p}$. XXX). I will leave it to readers to judge if I have made a misleading claim.

\section{Falsifiability and a common logic of inquiry}

Let us turn to Lizardo's comments which mainly address my reply to FJR, 'Understanding Social Status' (Chan, 2019b). Lizardo cannot make up his mind about my work on class and status. 'A lot of important results came out of this work' (p. XXX), he says. But he also thinks that the class-status debate is 'moribund' (p. XXX). 'This type "class analysis" provides insight, but it is also restrictive, and somewhat constipated in its implications' (p. XXX). Well, that sounds unhealthy. But just what is wrong with the classstatus literature?

According to Lizardo, '[t] he fundamental mistake made in the class analysis tradition was in proposing there was some particularly privileged way of splitting people up into clumps' ( $\mathrm{p}$. XXX). It is true that social class and social status are constructs developed by sociologists, and just like any other sociological constructs, 'there's nothing ontologically privileged about [them]' (p. XXX). This means that people who develop, defend, and use any social class scheme or social status scale need to demonstrate that their favourite construct helps us understand important aspects of society. But how do we 
do that except by developing internally consistent and empirically falsifiable claims from those constructs, and then testing those claims with high-quality data? For this reason, I think Lizardo is too glib when he dismisses my concern for the very low response rate of FJR's survey, or when he suggests that FJR's mistake is in not making a 'clean enough break' with 'Chan's (regression-based) pleads [sic] for "falsifiability", "testing of competing arguments", and "evaluation"' (p. XXX).

Let me expand on the last point. King et al. (1994) make a powerful case that all social science research, whether quantitative or qualitative, follows the same logic of inquiry. That common logic of inquiry, I would argue, applies to Bourdieusians too. No scientific claim, irrespective of research method or theoretical tradition, stands outside of the demand for falsifiability; nor can it claim immunity from rigorous evaluation against competing arguments. So it seems extraordinary to me that Lizardo brushes aside the issues that I raise in Chan (2019b) and claims that FJR and I are just offering 'two competing visions on how to do rigorous social science' (p. XXX).

Lizardo's view is linked to a point raised by Lambert who suggests that the different conclusions that FJR and I draw 'flow to a large degree from their divergent methodological strategies' (p. XXX). It also echoes Wuggenig's (2007) claim that Bourdieu's argument cannot be tested with 'mainstream' or 'Anglo-Saxon' social science methods.

The methodological contrast that Lambert, Lizardo, and Wuggenig refer to is way over-drawn. This is because, as Chan and Goldthorpe (2007) observe, multiple correspondence analysis is the categorical counterpart of principal component analysis (see Gower and Hand, 1996, chap. 4). Indeed, Goodman (1996, p. 408) points out that many tools for analysing the association in contingency tables, including log-linear models and correspondence analysis 'can be viewed as special cases of [a] general method of analysis.'

More substantively, Lizardo's criticism of the class-status distinction relates to his adoption of David Grusky's microclass proposal. 'What Chan and Goldthorpe call "class" and "status" (or any other so-called "big class" assignment) is always going to be some agglomeration ... over occupations (Durkheimian "microclasses" ... )' (p. XXX). 'Just like the story of David and Goliath, small wins against the big' (p. XXX).

It is beyond of the scope of this rejoinder to assess Grusky's microclass approach in any detail (but see Erikson et al., 2012). However, consider this extraordinary claim of Lizardo: 'the worst thing American stratification researchers ever did was to lump together these really nice, socially and phenomenologically valid classes ...to create little $5 \times 5$ tables featuring such meaningless lumps as "Managerial/Professional" all so they could fit a loglinear model and get an $L$-squared statistic' (p. XXX). 
Can it possibly be true that 'managerial/professional' is a meaningless category, or that fitting loglinear models to $5 \times 5$ mobility tables was the worst thing that stratification researchers (American or otherwise) ever did?

I think Grusky himself disagrees with Lizardo. In a paper on microclass mobility in four countries, Grusky and his colleagues report that '[b]y both $L^{2}$ and BIC criteria, we find that the microclass coefficients prove to be especially costly to excise [from descriptive models of class mobility pattern], although the big-class and gradational coefficients should not be excluded either.' (Jonsson et al., 2009, pp. 1002-1004, emphasis added).

Let me spell this out. If you have lots of data and can classify parents and children to big classes and microclasses, you will be able to see particularly strong tendencies for immobility in certain microclasses. But even after you have taken into account all the microclass details, you still need to know which big class (of which managerial/professional is one) people are members of, and their socioeconomic status, in order to achieve a good description of the class mobility pattern.

\section{$5 \quad$ Two pleas}

I think it was Max Planck who says something to the effect of 'science makes progress funeral by funeral.' What he means is that scientists rarely change their mind, even if (or, especially when) their theories have clearly been refuted by evidence. It is only when a younger generation of scientists gradually replaces the older generation that the long discredited theories die out.

So I am not optimistic that this rejoinder will persuade my colleagues in this special section. But I hope it speaks to younger colleagues in the field. Equally, my views might be wrong. If someone comes along and shows me the error of my ways, I hope I would have the good grace and integrity to admit my mistakes and move on. Time will tell.

I will finish with two pleas. First, as we debate Bourdieu, distinction, omnivorousness, and so on, let us not over-indulge in the game of what Bourdieu really means, what true distinction actually is, and so on. Bourdieu writes a lot, much of it not very clearly. If we treat him as a prophet, and squint at the holy texts hard enough and long enough, we could have any number of interpretations of Bourdieu to suit any theoretical position. But that is not a productive thing to do. Exegesis, I believe, is best left to the theologians. Secondly, let us hold on to the basics of good (social) science. At a minimum, demand of everyone in the debate internally consistent and empirically falsifiable claims to be tested with high quality data. Let's do more science, and less exegesis, please. 


\section{References}

Bennett, T., Savage, M., Silva, E., Warde, A., Gayo-Cal, M., and Wright, D. (2009). Culture, Class and Distinction. Routledge, London.

Booth, R. and Mohdin, A. (2019). Shared ownership households complain of housing segregation. The Guardian. Published 1 April 2019, retrieved 15 April 2019.

Bourdieu, P. (1984). Distinction: A Social Critique of the Judgement of Taste. Routledge \& Kegan Paul, London.

Chan, T. W. (2019a). Understanding cultural omnivores: social and political attitudes. British Journal of Sociology, 70(3), XXX-XXX.

Chan, T. W. (2019b). Understanding social status: a reply to Flemmen, Jarness and Rosenlund. British Journal of Sociology, 70(3), XXX-XXX.

Chan, T. W. and Goldthorpe, J. H. (2007). Data, methods and interpretation in analyses of cultural consumption: a reply to Peterson and Wuggenig. Poetics, 35(4).

Chan, T. W. and Turner, H. (2017). Where do cultural omnivores come from: the implications of educational mobility for cultural consumption. European Sociological Review, 33(4), 576-589.

Collison, P. (1963). The Cutteslowe Walls: A Study in Social Class. Faber and Faber, London.

DiMaggio, P. (1996). Are art-museum visitors different from other people? The relationship between attendance and social and political attitudes in the United States. Poetics, 24(2-4), 161-180.

Erikson, R., Goldthorpe, J. H., and Hällsten, M. (2012). No way back up from ratcheting down? A critique of the 'microclass' approach to the analysis of social mobility. Acta Sociologica, 55(3), 211-229.

Goodman, L. A. (1996). A single general method for the analysis of crossclassified data: reconciliation and synthesis of some methods of Pearson, Yule, and Fisher, and also some methods of correspondence analysis and association analysis. Journal of the American Statistical Association, 91(433), 408-428.

Gower, J. C. and Hand, D. J. (1996). Biplots. Chapman \& Hall, London. 
Grant, H. (2019). Too poor to play: children in social housing blocked from communal playground. The Guardian. Published 25 March 2019, retrieved 15 April 2019.

Jonsson, J. O., Grusky, D. B., Di Carlo, M., Pollak, R., and Brinton, M. C. (2009). Microclass mobility: social reproduction in four countries. American Journal of Sociology, 114(4), 977-1036.

King, G., Keohane, R. O., and Verba, S. (1994). Designing Social Inquiry: Scientific Inference in Qualitative Research. Princeton University Press, Princeton.

Osborne, H. (2014). Poor doors: the segregation of London's inner city flat dwellers. The Guardian. Published 25 July 2014, retrieved 15 April 2019.

Plowman, D., Minchinton, W., and Stacey, M. (1962). Local social status in England and Wales. Sociological Review, 10, 161-202.

Reeves, A. and de Vries, R. (2019). Can cultural consumption increase future earnings? Exploring the economic returns to cultural capital. British Journal of Sociology, 70(1), 214-240.

Schwartz, A. (2016). The "poor door" and the glossy reconfiguration of city life. The New Yorker. Published 22 January 2016, retrieved 15 April 2019.

Warde, A., Wright, D., and Gayo-Cal, M. (2007). Understanding cultural omnivorousness: or, the myth of the cultural omnivore. Cultural Sociology, $\mathbf{1}(2), 143-164$.

Wuggenig, U. (2007). Comment on Chan and Goldthorpe: pitfalls in testing Bourdieu's homology assumptions using mainstream social science methodology. Poetics, 35(4), 306-316. 